\title{
Medical Care at Mass Gatherings: Emergency Medical Services at Large-Scale Rave Events
}

\author{
Jan Krul, RN, MSc; ${ }^{1}$ Björn Sanou, MD, MSc; ${ }^{2}$ Eleonara L Swart, PharmD, PhD; ${ }^{3}$ \\ Armand R J Girbes, MD, PhD ${ }^{4}$
}

1. Educare Groningen, Groningen, The Netherlands

2. Department of Anesthesiology, Academic Medical Center, University of Amsterdam Amsterdam, The Netherlands

3. Department of Clinical Pharmacology and Pharmacy, University Hospital VU Medical Centre, Amsterdam, The Netherlands

4. Department of Intensive Care, University Hospital VU Medical Centre, Amsterdam, The Netherlands

\section{Correspondence: Jan Krul, RN, MSc Educare Groningen P.O. Box 1305 9701 BH Groningen The Netherlands E-mail: educare@home.nl}

Keywords: event medicine; mass gathering medicine; rave

\section{Abbreviations: \\ FAS: First Aid Station \\ GHB: Gamma-hydroxybutyrate \\ MUR: Medical Usage Rate \\ PPR: Patient Presentation Rate}

Received: November 21, 2011

Revised: January 8, 2012

Accepted: January 29, 2012

Online publication: April 17, 2012

doi:10.1017/S1049023X12000271

\section{Abstract}

Objective: The objective of this study was to develop comprehensive guidelines for medical care during mass gatherings based on the experience of providing medical support during rave parties.

Methods: Study design was a prospective, observational study of self-referred patients who reported to First Aid Stations (FASs) during Dutch rave parties. All users of medical care were registered on an existing standard questionnaire. Health problems were categorized as medical, trauma, psychological, or miscellaneous. Severity was assessed based on the Emergency Severity Index. Qualified nurses, paramedics, and doctors conducted the study after training in the use of the study questionnaire. Total number of visitors was reported by type of event.

Results: During the 2006-2010 study period, 7,089 persons presented to FASs for medical aid during rave parties. Most of the problems (91.1\%) were categorized as medical or trauma, and classified as mild. The most common medical complaints were general unwell-being, nausea, dizziness, and vomiting. Contusions, strains and sprains, wounds, lacerations, and blisters were the most common traumas. A small portion $(2.4 \%)$ of the emergency aid was classified as moderate (professional medical care required), including two cases $(0.03 \%)$ that were considered life-threatening. Hospital admission occurred in $2.2 \%$ of the patients. Fewer than half of all patients presenting for aid were transported by ambulance. More than a quarter of all cases $(27.4 \%)$ were related to recreational drugs.

Conclusions: During a five-year field research period at rave dance parties, most presentations on-site for medical evaluation were for mild conditions. A medical team of six healthcare workers for every 10,000 rave party visitors is recommended. On-site medical staff should consist primarily of first aid providers, along with nurses who have eventspecific training on advanced life support, event-specific injuries and incidents, health education related to self-care deficits, interventions for psychological distress, infection control, and disaster medicine. Protocols should be available for treating common injuries and other minor medical problems, and for registration, triage, environmental surveillance and catastrophe management and response.

Krul J, Sanou B, Swart EL, Girbes ARJ. Medical care at mass gatherings: Emergency Medical Services at large-scale rave events. Prehosp Disaster Med. 2012;27(1):71-74.

\section{Introduction}

Large public gatherings such as sporting events, concerts, and parties are becoming increasingly common. These events, called mass gatherings, have been defined as public events attended by a large number of persons. ${ }^{1,2}$ Event attendees typically are isolated from regular services and medical care.

Rave parties, also known as raves or dance events, with disk jockey-directed, fastpaced electronic music and light shows, are attended by approximately 800,000 people per year in the Netherlands. ${ }^{3}$ These parties are held at night during the winter, and in the daytime in summer. They typically last nine to 12 hours, and attract 3,000 to 60,000 visitors per event. In the Netherlands, rave parties are allowed on the condition that preventive measures, including the presence of an effective medical service system, are taken. 
Medical Care at Mass Gatherings

The medical care resources required for mass gatherings have been expressed in various ways. In the United States, the term Medical Usage Rate (MUR) is commonly used, and is defined as the number of first aid attendees per 10,000 event visitors. ${ }^{4,5}$ In a nine-year survey at raves in the Netherlands, the average MUR was 79 (range $=59-170) .{ }^{6}$ Other countries use Patient Presentation Rates (PPRs), which are calculated as the number of patients per 1,000 event visitors presenting to on-site health care services. ${ }^{2}$ Reported PPRs at First Aid Stations (FAS) vary from 0.14 to 90 , but most reported ranges are between 0.5 and two per 1,000 visitors. PPRs have been described as eventspecific. $^{2}$

Mass gatherings can generate many patients for general practitioners, ambulance services, and hospitals. Therefore, health care planning is important for all involved health service providers, in order to allow for timely treatment on-site and to provide adequate referral and transport resources. To reduce hospital admittance and ambulance transport, event medical services are designed to provide: (1) first aid; (2) advanced life support; (3) health education and prevention; (4) hygiene monitoring and infection control; and (5) disaster planning.

The primary purpose of this study was to establish comprehensive guidelines for medical care during these types of mass gatherings, based on previous experience of medical support during rave parties. A secondary objective was to confirm earlier findings regarding health problems at mass gatherings. 6,7

\section{Methods}

\section{Design and Participants}

This was a prospective, observational study of self-referred patients who reported to FAS during Dutch rave parties in the period 2006 through 2010. All those presenting for medical care were registered into the study. An existing standard registration questionnaire was used to record the reported health problems. All cases were scored using a two-dimensional framework. First, incidents were categorized as medical, trauma, psychological, or miscellaneous. Second, based on the Emergency Severity Index, each incident was classified as (1) mild (defined as an absence of professional medical care needs); (2) moderate (professional medical care required); or (3) severe (life-threatening). ${ }^{8-10}$

Qualified nurses, assisted by paramedics and physicians, all with additional specific training on party-related risks such as self-care deficits and drug use, examined patients. Members of staff of the FAS were trained in using the study questionnaire, and attended an introduction course, along with an annual refresher and update course. A staff member specifically appointed to provide assistance in filling out the questionnaires coached all other staff members. Mistakes and inconsistencies in data collection were corrected on-scene.

\section{Procedure}

After entering FAS, attendees were received by a front desk officer who asked each patient about his complaint, injury, or question. Some visitors attended the FAS for self-treatment (e.g., they asked for a band-aid to avoid blisters or asked for a painkiller to relieve headache); these cases were not assessed as medical problems. All other attendees were transferred to a member of the medical staff who assessed health problems. All data were registered in a standard questionnaire.

After a patient was discharged from a FAS or transferred to ambulance personnel for hospital transport, a staff member

\begin{tabular}{|l|c|c|c|}
\hline & $\begin{array}{c}\text { Mild } \\
\mathbf{n}(\%)\end{array}$ & $\begin{array}{c}\text { Moderate } \\
\mathbf{n ~ ( \% )}\end{array}$ & $\begin{array}{c}\text { Severe } \\
\mathbf{n}(\%)\end{array}$ \\
\hline Medical & $2,484(35.0 \%)$ & $110(1.6 \%)$ & $1(0.0 \%)$ \\
\hline Trauma & $3,975(56.1 \%)$ & $25(0.4 \%)$ & $0(0.0 \%)$ \\
\hline Psychological & $83(1.2 \%)$ & $10(0.1 \%)$ & $0(0.0 \%)$ \\
\hline Miscellaneous & & & \\
\hline
\end{tabular}

Table 1. Categorized and classified health problems $(\mathrm{N}=7,089)^{\mathrm{a}}$

a83 (1.2\%) persons were neither categorized nor classified; no current health-related incident was found.

bPercentages do not add up to 100 due to rounding

${ }^{\mathrm{c}}$ Medical and/or trauma and/or psychological

assigned to verify registration checked all data on the study form. This person also classified the incident as mild, moderate or severe, and categorized it as medical, trauma, psychological, or miscellaneous.

\section{Statistics}

Descriptive statistics and analysis were used to process study data. All analyses were performed using SPSS version 17.0 (SPSS Inc, Chicago, IL, USA).

\section{Results}

During the study period, a total of 7,089 patients presented at FAS with a medical problem. This included 292 patients (4.1\%) with recurrent problems (i.e., they revisited the FAS for the same health problem) and 1,479 patients (20.9\%) with a problem that existed before the party started.

\section{Demographics}

The mean age of FAS attendees was 23.9 years (range, 12-85 years). Slightly more men $(3537=49.9 \%)$ than women $(3523=$ 49.7\%) visited a FAS. In 29 cases, gender was not mentioned in the case record form.

\section{Clinical Features}

A total of 6,459 (91.1\%) FAS visitors were categorized as medical or trauma and classified as mild (Table 1). Mild medical presentations included non-specific symptoms of "unwell-being" (21.8\% of all FAS visitors with health problems), nausea (9.1\%), dizziness (4.6\%), vomiting (6.2\%), and gastric/stomach ache (5.9\%). Mild trauma presentations included contusions/sprains/ strains (most commonly ankle, lower back, and knee), accounting for $20.8 \%$ of all FAS visitors with health problems; wounds and lacerations (11.3\%); blisters and skin injuries (11.6\%, mostly located on the heel); and insect bites or stings (4.6\%). In the mild psychological category, presentations were anxiety $(2.2 \%)$, disorientation (1.0\%), and agitation (0.8\%). In some cases, psychological problems occurred together with trauma or medical problems; these cases were categorized as miscellaneous.

A total of $171(2.4 \%)$ cases were classified as moderate and required professional medical care, while two cases (0.03\%) were considered life-threatening (Table 1). Moderate presentations included cases involving altered consciousness (94/171, 54\%), all of which were related to substances such as gammahydroxybutyrate (GHB), alcohol, and ecstasy (used alone or in combination). The most common moderate trauma cases were fractures $(12 / 25,48 \%)$, wounds $(3 / 25,12 \%)$, eye injuries $(3 / 25$, 
$12 \%)$, and multiple trauma $(4 / 25,16 \%)$. Of the 10 moderate psychological cases, six were excited delirium, three were psychotic delusions, and one was severe anxiety.

Both life-threatening cases were related to recreational drugs. No deaths were reported. Apart from the First Aid attendees with medical problems, approximately 2,500 visitors attended for self-treatment. They asked for painkillers, band-aids, sanitary napkins, tampons, or hearing protection.

\section{Clinical Referrals}

Hospital referral occurred for 158 (2.2\%) First Aid attendees of which $48(0.7 \%)$ were transported by ambulance.

\section{Health Disturbance-Related Factors}

A number of First Aid attendees receiving medical evaluation reported self-care deficits as defined in the Handbook of Nursing Diagnosis. ${ }^{11}$ Among all presenting patients, 5.7\% were found with altered nutrition (less than recommended body requirements), $3.6 \%$ with sleep pattern disturbance, and $2.1 \%$ with fluid volume deficit.

More than a quarter of all evaluated cases $(27.4 \%)$ were recreational drug-related, involving substances used alone or in combination. Most-used substances included alcohol (17.8\%), ecstasy (11.6\%), or GHB (3.3\%). Use of amphetamines, cannabis, cocaine, and mushrooms was also reported.

A total of $1.5 \%$ of the party visitors suffered from asthma or diabetes and accessed the FAS (primarily for forgotten medication). Weather and indoor climate conditions influenced the MUR. Health complaints increased with high temperature, and even more when relative humidity was $>85 \%$.

\section{Staffing}

Two-thirds of all patients presented to the FAS from three to eight hours after the start of the rave. Based on maximum peak load during these five hours, six health care providers were required for every 10,000 party visitors to eliminate waiting time.

\section{Discussion}

During the nine- to 12-hour raves included in this study, many party visitors presented to FAS. For every 1,000 persons, eight to 12 presented to the medical facility on-site (self-treatment attendees included). Apart from generally occurring health complaints, rave party-specific problems can be identified. Most are minor injuries or minor medical conditions that can be managed with basic first aid providers. However, including health professionals in addition to first aid providers and providing specific event-related training are recommended to avoid unnecessary hospital admittance and to provide more services on-site.

The comprehensive guidelines and recommendations below were developed based on the experience of providing medical support during raves.

\section{First Aid}

Some minor problems, such a superficial wounds and lacerations, occur regularly. Providing wound care, including tetanus prophylaxis, should be considered essential for such events. In this study, there were many soft tissue injuries of the ankle and knee. Therefore, event care providers should be aware of the Ottowa Ankle Rules ${ }^{12}$ and Ottawa Knee Rules ${ }^{13,14}$ to determine the need for radiographic referral. During the summer, event visitors are often stung or bitten by insects; therefore, protocols should provide guidelines for anaphylaxis treatment.

Instructions for coping with lower back pain and blisters should be developed, as well as how to deal with headache. Most visitors suffering from headache only asked for an analgesic and were not assessed as patients in our study. First Aid Station staffs should be aware that for every three First Aid visitors, one additional person will ask for a self-care aid. On-site medical staff should consider in advance which complaints can be selftreated safely.

\section{Advanced Life Support}

Although life-threatening emergencies are rare, medical staff should be prepared for unconscious patients and occasional specific severe health emergencies such as excited delirium. For excited delirium, all severe cases in this study were substancerelated. Most unconscious patient presentations were related to $\mathrm{GHB}$, alcohol, or ecstasy intake. ${ }^{15}$

\section{Health Education and Prevention}

First Aid attendees at raves suffer from various minor problems. However, to avoid complications, professional health care providers should perform a full assessment for each attendee. Because some patients suffer from mild psychological distress, first aid personnel should be trained to perform specific interventions such as anxiety reduction and reality orientation. Staff should also be prepared to provide health education, and have knowledge about the most common recreational drugs and drug-related health disturbances, especially because drug-using attendees may stay significantly longer in the FAS. Party visitors are young, and some are not aware of basic health requirements including needs for nutrition, water intake and prevention of hyponatremia, ${ }^{16-18}$ and the balance between rest and activity.

\section{Hygiene Monitoring and Infection Control}

Environmental elements should be monitored such as weather (or climate at an indoor event) and venue hygienic situation (toilets, hand washing, and food). Many First Aid attendees suffer from gastrointestinal problems. They should be diagnosed carefully, and food-borne illness should be identified immediately to avoid an event-specific outbreak.

\section{Extreme Emergencies}

Typically, Emergency Medical Services, together with other public safety and security agencies, are required to manage both a relatively predictable patient load as well as unexpected and catastrophic events at mass gatherings. Disaster planning must be a part of the preparation for mass gatherings. Health care management designs should incorporate a specific catastrophe response plan in which all possible scenarios are anticipated.

\section{Environment}

Environmental factors contribute to the health challenges for those attending mass gatherings. Temperature and humidity correlate to the number of First Aid attendees at large-scale events. The relationship with temperature is complex, but with temperatures of $30^{\circ} \mathrm{C}$ or higher, patient presentations increase. The relationship between higher humidity and an increased number of patients appears to be significant. Other influences are the availability of alcohol, and the mobility and activity of the crowd. ${ }^{1}$ 
Consequences for Staff and Procedures

Sanders et a $1^{19}$ and Arbon ${ }^{1,20}$ have recommended standards for patient care services at mass gatherings, and stated that these standards need review. The current study confirms the staffing need for six health care providers for every 10,000 visitors. However, this includes operational officers, but excludes management staff. Arbon divided medical staff as follows: $88.8 \%$ first aid providers (of which half had advanced first aid training), 7.2\% nurses, $2.7 \%$ ambulance officers, and $1.3 \%$ medical practitioners. ${ }^{1}$ Based on the nature of health problems observed at Dutch raves, the authors of this study recommend $50 \%$ first aid providers and 50\% nurses, both with additional training. In addition, a physician should be added for every 10,000 visitors and an ambulance team for every 15,000. First aid providers can treat minor injuries and support First Aid attendees who are in psychological distress. Nurses are needed for triage, health assessment, education and coaching, hygiene surveillance, and for intervention for more severe cases. The medical team should include two Advanced Life Supported-trained professionals for every 15,000 visitors, as well as one nurse with mental health care experience.

In addition to the typical first aid and resuscitation equipment, protocols and materials must be available for registration and triage. Protocols for management of wound care, ankle and knee injuries, back pain, headache, blister management, anaphylaxis, environmental issues (weather/climate, and water and food hygiene) are recommended, as well as a catastrophe response plan.

\section{References}

1. Arbon P, Bridgewater FHG, Smith C. Mass gathering medicine: a predictive model for patient presentation and transport rates. Prehosp Disaster Med. 2001;16(3):109-116.

2. De Lorenzo RA. Mass gathering medicine: a review. Prehosp Disaster Med. 1997;12(1):68-72.

3. Gram H, Jongedijk S, Olthof S, Reinders A, van Schubert D. Dance in Nederland. De betekenis en impact van dance op de Nederlandse economie en maatschappij: Een verkenning. Amstelveen: KPMG; 2002.

4. Milsten AM, Maguire BJ, Bissel RA, Seaman KG. Mass-gathering medical care: a review of the literature. Prehosp Disaster Med. 2002;17(3):151-162.

5. Milsten AM, Seaman KG, Liu P, Bissel RA, Maguire BJ. Variables influencing medical usage rates, injury patterns, and levels of care for mass gatherings. Prehosp Disaster Med. 2003;18(4):334-346.

6. Krul J, Girbes ARJ. Experience of health-related problems during house parties in the Netherlands: nine years of experience and three million visitors. Prehosp Disaster Med. 2009;24(2):133-139.

7. Krul J, van Litsenburg R. Medische zorg tijdens dance-events. Critical Care. 2010. 2010:22-26.

8. de Boer J. Rampengeneeskunde. Een samenvattend overzicht. Spoedeisende en rampengeneeskunde. Amsterdam: VU Uitgeverij; 2001:179-191.

9. Christ M, Grossmann F, Winter D, Bingisser R, Platz E. Modern triage in the emergency department [in German]. Dtsch.Arztebl.Int. 2010;107(50):892-898.

10. van dW, I, Rullmann HA, Leenen LP, van Stel HF. Associations of the Emergency Severity Index triage categories with patients' vital signs at triage: a prospective observational study. Emerg Med J. 2010:28(12):1032-1035.

11. Carpenito LJ. Handbook of Nursing Diagnosis. Philadelphia: J B Lippencott Company; 1991.

12. Bachmann LM, Kolb E, Koller MT, Steurer J, ter Riet G. Accuracy of Ottawa ankle rules to exclude fractures of the ankle and mid-foot: systematic review. BMJ. 2003;326(7386):417.

\section{Limitations}

This study was conducted in the Netherlands and may not be valid for other countries. In addition, the study was limited to data obtained at rave parties. While the study sample is large, it includes only self-referrals and does not provide a complete overview of all health disturbances at rave parties. It is possible that a number of persons suffered from complaints, but did not visit the FAS. Wijngaart et al and de Bruin et al found some party visitors sought help from friends, security personnel, or catering staff. ${ }^{21-23}$ Further, some visitors with health complaints may have gone directly to their general practitioners or a hospital emergency room instead of the on-scene FAS.

\section{Conclusion}

During a five-year field period, most on-site presentations for medical evaluation at rave dance parties were for mild conditions. A medical team of six health care workers for every 10,000 rave party visitors is recommended. On-site medical staff should consist primarily of first aid providers and nurses with event-specific training in advanced life support, injuries, health education for self-care deficits, interventions with psychological distress, infection control, and disaster medicine. Protocols should be available for treating common injuries and minor medical problems, and for registration, triage, environmental surveillance, and catastrophe management and response.

13. Jalili M,.Gharebaghi H. Validation of the Ottawa Knee Rule in Iran: a prospective study. Emerg Med J. 2010;27(11):849-851.

14. Robb G, Reid D, Arroll B, Jackson RT, Goodyear-Smith F. General practitioner diagnosis and management of acute knee injuries: summary of an evidence-based guideline. $N$ Z.Med J. 2007;120(1249):U2419.

15. Krul J, Girbes A. Gamma-hydroxybutyrate: experience of 9 years of gammahydroxybutyrate (GHB)-related incidents during rave parties in The Netherlands. Clin.Toxicol.(Phila). 2011;49(4):311-315.

16. Aramendi I,.Manzanares W. Hyponatremic encephalopathy and brain death in Ecstasy (3,4-methylenedioxymethamphetamine) intoxication [in Spanish]. Med Intensiva. 2010;34(9):634-635.

17. Hsu YJ, Chiu JS, Lu KC, Chau T, Lin SH. Biochemical and etiological characteristics of acute hyponatremia in the emergency department. J Emerg Med 2005;29(4):369-374.

18. Rosenson J, Smollin C, Sporer KA, Blanc P, Olson KR. Patterns of ecstasyassociated hyponatremia in California. Ann Emerg Med. 2007;49(2):164-171.

19. Sanders AB, Criss E, Steckl P, Meislin HW, Raife J, Allen D. An analysis of medical care at mass gatherings. Ann Emerg Med. 1986;15(5):515-519.

20. Arbon P. Planning medical coverage for mass gatherings in Australia: what we currently know. J Emerg Nurs. 2005;31:346-350.

21. de Bruin D, Maalste NJM, van de Wijngaart GF. Goed fout gaa; : Eerste hulp op grote dansevenementen. Utrecht: CVO; 1998.

22. van de Wijngaart GF, Braam R, de Bruin D, et al. Ecstacy in het uitgaanscircuit. Utrecht: CVO; 1997.

23. van de Wijngaart GF, Braam R, de Bruin D, Fris M, Maalste NJM, Verbraeck HT. Ecstasy use at large-scale dance events in the Netherlands. J Drug Issues. 1999;29(3):679-702 